34 Danne T, Grüters A, Schuppan D, Quantas N, Enders I, Weber B. Relationship of procollagen type III propeptiderelated antigens in serum to somatic growth in healthy children and patients with growth disorders. 7 Pediatr 1989; 114: 257-60.

35 Trivedi P, Hindmarsh P, Risteli J, Risteli L, Mowat AP, Brook CGD. Growth velocity, growth hormone therapy, and serum concentrations of the amino-terminal propeptide of type III procollagen. $\mathcal{F}$ Pediatr 1989; 114: 225-30. 36 Trivedi P, Risteli J, Risteli L, Hindmarsh PC, Brook CGD, Mowat AP. Serum concentrations of the type I and III procollagen propeptides as biochemical markers of growth procollag in propepth disorders. Pediatr Res 1991; 30: 276-80.

\title{
Neonatal screening for toxoplasmosis
}

It is possible that screening newborn babies for toxoplasmosis and treating those with confirmed congenital infection might stop some of them getting later eye, ear, or brain disease. A screening programme using the heelprick filter paper blood samples collected for routine biochemical screening and testing for IgM antibodies to toxoplasma was begun in Massachusetts in 1986 and in New Hampshire in 1988 (Nicholas G Guerina and colleagues, New England Fournal of Medicine 1994; 330: 1858-63). Up to July 1992 some 645000 babies were screened. One hundred tests were positive but on further investigation only 50 babies were shown to have congenital infection. All of these 50 were normal on routine neonatal examination but nine had retinal lesions on ophthalmological assessment.

Five babies with severe toxoplasma brain disease were identified independently of the screening programme. Only two of these had a positive IgM antibody screening test.

Forty six children completed a 12 month course of treatment with pyrimethamine, leucovorin, and either sulphadiazine or spiramycin. Thirteen had anaemia, neutropenia, or both during treatment, one developed a rash, and one was inadvertently given an excessive dose of pyrimethamine. Four children apparently developed new retinal lesions on or following treatment. As there was no untreated group the effectiveness of the treatment is not known. It is suggested that these children did well in comparison with those in previous follow up studies of untreated children.

The screening test, therefore, was negative in $60 \%$ of children with grossly symptomatic congenital infection and $50 \%$ of positive tests were apparently false positives. Treatment is not devoid of problems and whether it is effective is uncertain. There seems to be a lot more work to be done before the authors' (muted) enthusiasm is likely to be shared by many.

ARCHIVIST 